\title{
A invisibilidade da violência contra crianças e adolescentes: análise cartográfica do fenômeno em município da Fronteira Oeste do Rio Grande do Sul
}

\author{
The invisibility of violence against children and adolescents: \\ cartographic analysis of the phenomenon in the municipality of the Western Frontier of Rio \\ Grande do Sul
}

\section{Resumo}

O presente artigo apresenta os resultados de uma pesquisa que objetivou mapear as expressões de violência contra o segmento infantojuvenil e as estratégias para o enfrentamento em um município da Fronteira Oeste do Rio Grande do Sul. A pesquisa teve enfoque qualitativo do tipo descritivoexplicativo, utilizando-se da cartografia, com o intuito de construir uma conexão entre os dados e a possibilidade de identificação por inferência das características da violência. A análise em documentos de atendimento possibilitou apreender sobre como as práticas institucionais de atendimento produzem o silenciamento e invisibilização das particularidades envoltas na violência contra crianças e adolescentes, incidindo em uma lacuna de informações, que são essenciais para a formulação de políticas públicas de proteção.

Palavras-chave: Violência; Criança e Adolescente; Registros Institucionais.

\begin{abstract}
This article presents the results of a research that aimed to map the expressions of violence against children and adolescents and strategies for coping in a city on the Western Frontier of Rio Grande do Sul. The research had a qualitative focus of the descriptive-explanatory type, using cartography, in order to build a connection between the data and the possibility of identification by inference of the characteristics of violence. The analysis in care documents made it possible to learn about how institutional care practices produce the silencing and invisibility of the particularities involved in violence against children and adolescents, focusing on an information gap, which are essential for the formulation of public protection policies.
\end{abstract}

Keywords: Violence; Child and Adolescent; Institutional Records.

\footnotetext{
* Doutora em Serviço Social pela PUCRS. Professora dos cursos de Serviço Social e Ciências Humanas da Universidade Federal do Pampa.

** Doutora em Serviço Social pela Universidade do Estado do Rio de Janeiro. Professora Adjunta da Escola de Serviço Social da Universidade Federal do Estado do Rio de Janeiro.

*** Pós-Doutora em Serviço Social pela PUCRS. Professora do curso de Serviço Social da Universidade Federal do Pampa.
} 


\section{Introdução}

A violência contra crianças e adolescentes é um fenômeno arraigado na cultura brasileira, presente e reproduzido por diversas determinações, entre elas, citam-se as principais: educação adultocêntrica (superioridade do adulto sobre a criança), falocrática (relações desiguais de gênero dentro da família) e androcêntrica (supervalorização do homem).

A intensificação do processo de reprodução da violência correlaciona-se às mudanças societárias centradas na volatilidade, fluidez e superficialidade das relações interpessoais, profundamente, atingidas pela exploração do trabalho e pelo avanço tecnológico e informacional. Crianças e adolescentes são cotidianamente vitimizadas por múltiplas expressões de violência que se espraiam pela internet, tais como: cyberbullying (flaming, cyberstalking, outing, fake) e a violação à dignidade sexual (sexting, revenge porn, aliciamento de crianças e adolescentes, pornografia infantil e pedofilia).

Vivencia-se uma amplificação extrema de processos de degradação da humanidade, via o recrudescimento das desigualdades (socioeconômicas, gênero, geração, cultural e territorial), aviltamento de direitos e liberdades e a retomada de valores e posturas antidemocráticas.

Quando se considera que a violência, em suas mais diversas expressões, acompanha as transformações societárias, é necessário um contra movimento de edificação de estratégias que paulatinamente incidam para a proteção das crianças e adolescentes e responsabilização dos/as autores/as da violência. Nessa miríade que engloba a díade proteção/responsabilização, o que se vislumbra, hodiernamente, é a ausência de medidas efetivas de promoção aos direitos das crianças e adolescentes a uma vida sem violência, logo, tais ações centram-se apenas em atendimentos residuais após a instauração da violência.

A violência é um fenômeno extremamente complexo. Medidas simples, não cabem para o seu real enfrentamento. Não tem como simplificar um processo que historicamente emitiu raízes profundas na forma de sociabilidade no Brasil. Nesse sentido, pode-se entender que:

Crianças e adolescentes, naturalmente, por uma questão de desenvolvimento pessoal, são vulneráveis. Mulheres, em algumas sociedades mais do que em outras, podem estar em situação de vulnerabilidade. Isto depende do grau de empoderamento, acesso à educação e trabalho, e aos direitos civis, políticos e sociais das mulheres, que diferem em cada sociedade. Migrantes em geral também são 
considerados como um público vulnerável, principalmente aqueles que estão em situação irregular. Minorias étnicas, indígenas, pessoas com deficiência e a população LGBT podem também estar em situação de vulnerabilidade em alguns contextos (BRASIL, 2018, p. 131).

A violência espraia-se transversalmente pela sociedade, porém há historicamente grupos e contextos que se encontram mais suscetíveis a vivenciarem a violência em toda sua intensidade e perversidade. Outros aspectos que a particularizam dizem respeito ao território, à cultura, à presença ou não de políticas públicas.

Em pesquisa documental realizada no ano de 2018, nos relatórios de registros de denúncia do Disque Direitos Humanos (Disque 100), entre os anos de 2016 a 2017, verificouse uma diminuição de $45,71 \%$ nos registros em nível nacional. A realidade sul rio-grandense expressa um índice significativo de queda nas denúncias, em torno de 54,98\%, ficando atrás apenas dos estados do Acre $(56,63 \%)$ e do Amazonas (56,21\%).

Em um primeiro momento, pode-se incorrer ao equívoco de apreender que a violência contra crianças e adolescentes vem diminuindo significativamente no cenário brasileiro, ou seja, que o decréscimo nos registros sinalizaria uma importante redução de situações violadoras dos direitos infantojuvenis. Contudo, em um movimento mais crítico e de análise mais acurada, é possível perceber que, por detrás desse engodo, existe um grave problema, que é a subnotificação da violência.

A ausência de dados sobre o fenômeno não é uma realidade somente do Brasil. Mesmo em países com maior organização dos serviços de proteção, é um desafio romper com o ocultamento das situações de violência contra a criança e adolescente (BEN NATAN et al., 2012).

A invisibilidade da violência implica a ausência de estratégias capazes de enfrentar o fenômeno nas manifestações cotidianas e instrumentalizar o poder público, com subsídios diagnosticais, acerca das suas particularidades, projetando assim, ações compactuadas com a proteção integral das crianças e adolescentes.

Construir dados estatísticos e dimensionais da violência é um dos grandes desafios que, tanto o poder público quanto à sociedade civil brasileira devem acarar. Para enfrentar, é preciso conhecer, apreender seus contornos, particularidades, complexos causais, identificar, descrever e explicar o fenômeno em sua totalidade.

A subnotificação implica não apenas à ausência de dados confiáveis para a 
formulação de políticas públicas, mas incide para que as situações de violência permaneçam na clandestinidade, vitimizando diariamente milhares de crianças e adolescentes que têm as vidas despedaçadas e ceifadas pela violência nas múltiplas expressões.

Pensar políticas públicas de enfrentamento à violência contra população infantojuvenil requer a participação ativa do Estado e da sociedade (controle social) no processo de planejamento, execução e avaliação das ações. Nesse tocante, o presente artigo não parte de conjecturas, mas de dados concretos sobre a realidade dessa expressão da questão social que assola muitas crianças e adolescentes.

O enfrentamento à violência nas mais complexas manifestações exige um esforço coletivo entre sociedade e Poder Público para dirimir ações que alcancem, de forma eficaz e efetiva, os determinantes que incidem para a presença desse fenômeno na vida da população infantojuvenil.

Esse processo requer políticas públicas e também o desenvolvimento de valores que a sociedade deve garantir para a proteção das crianças e adolescentes, tais como: solidariedade, dignidade e reconhecimento do outro que está em uma condição especial de desenvolvimento físico, psíquico e social e carece que a garantia do atendimento das necessidades seja realizado por intermédio dos adultos, sejam eles pais (sujeitos primários) ou profissionais (professores, psicólogos, assistentes sociais, médicos, etc.).

O olhar crítico possibilitado pela análise dos resultados da pesquisa propiciou identificar processos mais profundos e contraditórios que incidem sobre a proteção à criança e ao adolescente no munícipio. Torna-se imprescindível captar que a política pública seja um espaço de constante tensão e de correlações de forças no campo de luta por direitos, e que a efetividade se dá nessa arena contraditória de disputas de interesses.

Nesse sentido, o presente artigo busca dimensionar as principais características desse fenômeno no cenário fronteiriço, a partir da análise de registros institucionais entre os anos de 2016 e 2018/1, ressalta-se que o desvendamento dos meandros dessa violência e o reconhecimento social da existência na sociedade, contribuem para a construção de políticas públicas protetoras à infância e à juventude.

\section{O caminho metodológico}

A pesquisa teve enfoque qualitativo do tipo descritivo-explicativa, imprimiu nas análises a conexão entre os dados, buscando contemplar por meio do instrumento de análise 
A invisibilidade da violência contra crianças e adolescentes: Análise cartográfica do fenômeno...

documental a possibilidade de identificação por inferência as características da violência, o perfil das crianças, adolescentes, famílias e dos/as autores da violência, bem como as modalidades de atendimento e encaminhamento realizados no âmbito do atendimento.

A cartografia pressupõe a não rigidez na utilização de métodos e fixidez de metas no processo de investigação da realidade. Ao contrário, a riqueza situa-se na relação dialética entre o conhecer e o fazer, pesquisar e intervir, possibilitando ao/à pesquisador(a) maior dinamicidade no mergulho investigativo, transcendendo a pretensa neutralidade no ato de pesquisar e transmutando a investigação científica de um patamar de contemplação para a possibilidade real de intervenção.

\footnotetext{
A cartografia social aqui descrita liga-se aos campos de conhecimento das ciências sociais e humanas e, mais que mapeamento físico, trata de movimentos, relações, jogos de poder, enfrentamentos entre forças, lutas, jogos de verdade, enunciações, modos de objetivação, de subjetivação, de estetização de si mesmo, práticas de resistência e de liberdade. Não se refere a método como proposição de regras, procedimentos ou protocolos de pesquisa, mas, sim, como estratégia de análise crítica e ação política, olhar crítico que acompanha e descreve relações, trajetórias, formações rizomáticas, a composição de dispositivos, apontando linhas de fuga, ruptura e resistência (FILHO; TETI, 2013, p. 47).
}

O uso da cartografia contribuiu para apreender a violência contra crianças e adolescentes na multiplicidade espaço-temporal, desenhando as relações e dinâmicas envoltas na reprodução desse fenômeno sob a particularidade do território ora estudado. Além disso, a cartografia incide para "desemaranhar as linhas de um dispositivo é, em cada caso, traçar um mapa, cartografar, percorrer terras desconhecidas" (FILHO; TITE, 2013, p. 51), ou seja, problematizar, fazer a crítica, permitindo estabelecer conexões, identificar forças, relações, objetivações e subjetivações.

A coleta de dados foi realizada em prontuários (2013 a 2018/1) de uma instituição que atende crianças e adolescentes em situações de violência, fazendo-se uso de instrumento fechado com questões que possibilitem identificar as particularidades da violência, tais como: perfil da criança e adolescente, autor/a da violência bem como as modalidades de atendimento e encaminhamento.

O tipo de amostra utilizada para a escolha dos prontuários consistiu-se na não probabilística intencional que, segundo Gil (2007, p. 145), é uma amostra "com base em certas 
características tidas como relevantes pelos pesquisadores, mostra-se mais adequada para a obtenção de dados de natureza qualitativa".

Nesse sentido, os prontuários escolhidos seguiram os seguintes critérios de escolha:

- Prontuários de atendimento às situações de violência (sexual, física, psicológica, negligência e abandono) contra crianças e adolescentes;

- Prontuários de atendimento correspondentes ao período de 2013 a 2018/1.

Os critérios de exclusão, foram:

- Prontuários não preenchidos por assistentes sociais e/ou psicólogos;

- Prontuários que não possuíam descrição sintética dos atendimentos e encaminhamentos;

- Prontuários que não possuíam informações sobre a identificação da violência.

Sobre os riscos que a pesquisa, em dados secundários, pode ocasionar, salientam-se os seguintes:

- Estigmatização das crianças, adolescentes e famílias devido à divulgação de informações quanto à identificação;

- Invasão de privacidade;

- Divulgação de dados confidenciais;

- Risco à segurança dos prontuários.

Considerando os possíveis riscos, foram tomadas as seguintes providências:

- Capacitação da equipe de pesquisa que procedeu à coleta dos dados secundários na perspectiva científica e ética, a fim de prevenir a ruptura com o sigilo das informações contidas nos prontuários;

- Limitou-se o acesso aos prontuários apenas pelo tempo, quantidade e qualidade das informações específicas e necessárias para a pesquisa;

- Garantiu-se a integridade dos prontuários (danos físicos, cópias, rasuras);

- Assegurou-se a confidencialidade e a privacidade, a proteção ao anonimato dos/as usuários/as, garantindo a não utilização de informações em prejuízos dos/as usuários/as da instituição.

Conforme a Resolução 510/2016 da Comissão Nacional de Ética em Pesquisa (CONEP), que trata das particularidades das pesquisas em ciências humanas e sociais, no parágrafo único sobre a dispensa de submissão de projeto ao sistema CEP/CONEP, a pesquisa desenvolvida atendeu ao inciso $\mathrm{V}$, caracterizando-se como "pesquisa com bancos de dados, cujas informações são agregadas, sem possibilidade de identificação individual”, assim não necessitando de parecer do Comitê de Ética em Pesquisa (CEP).

\section{A importância do registro das informações para o enfrentamento à violência contra crianças e adolescentes}

A literatura científica vem se referindo, em vários estudos, que um dos principais 
obstáculos para a construção de medidas de proteção às crianças e adolescentes em situação de violência encontra-se na ausência de informações que possibilitem à elaboração de um quadro mais realístico sobre o fenômeno, com descrições fidedignas das particularidades e estratégias potenciais para o enfrentamento.

A ausência de informações diz respeito ao não registro ou um registro incompleto das situações que perpassam os serviços de notificação (responsáveis pelas denúncias). Essa lacuna constata-se também nos serviços de atendimento que, por falta de qualificação profissional ou por entender que a documentação, limita o agir profissional a uma prática burocratizada de preenchimento de planilhas, acaba por inviabilizar a construção de parâmetros sobre a violência, de estudos sistemáticos e avaliação contínua dos atendimentos.

O tratamento técnico das informações é a chave heurística para o conhecimento da realidade e estabelecimento de mediações entre as singularidades das situações e sua totalidade na análise macro do fenômeno da violência. Assim, os dados sistematizados pelos/as profissionais não serão entendidos de forma isolada, ou meramente quantitativa, ao contrário, possibilitam aos/às profissionais conexões essenciais que iluminarão as possibilidades concretas de intervenção.

Nesse sentido, os registros podem ser organizados:

[...] por meio de instrumentais que permitam armazenar um conjunto de informações pertinentes ao trabalho social desenvolvido, tais como: ações realizadas, situações atendidas, instrumentos, métodos e procedimentos adotados, encaminhamentos realizados e resultados atingidos. [...] algumas das informações ficarão restritas à Unidade, como os registros sobre o acompanhamento familiar em prontuários, enquanto outros dados e informações importantes para o monitoramento e/ou avaliação das ações realizadas, precisam ser compartilhados com o órgão gestor que, por sua vez, deverá agregá-los e sistematizá-los. [...] quando possível, que os registros e os fluxos de informação sejam organizados de forma padronizada e informatizada, com o intuito de agilizar e otimizar o processo de gestão, monitoramento e avaliação. O registro e acesso a informações deve observar a questão ética, a necessidade de segurança e sigilo de determinadas informações, além das recomendações dos conselhos de categoria profissional, sempre que couber (BRASIL, 2011, p. 56-57).

Torna-se necessário definir as técnicas e instrumentos que serão utilizados para os registros dos atendimentos (banco de dados interdisciplinar, prontuários, relatórios semanais, mensais e/ou anuais, arquivamentos, folha de coleta de dados, entre outros).

Quando a referência buscada é a integralidade, o registro ultrapassa a quantificação dos casos, sendo importante documentar elementos que impetrem os impactos e 
consequências da violência na vida dos/as usuários/as, os sofrimentos, anseios e medos, os modos de vida com os valores e crenças e, a partir disso, realizar as mediações necessárias para a construção de uma rede de proteção prevenindo a revitimização das crianças e adolescentes.

Para Nordenstahl (2008), existem dois níveis de vitimização: a primária e a secundária. A vitimização primária é resultante da ação da violência sexual e possui diversos impactos - físico, psicológico, social, etc. Entretanto, a vitimização secundária ou a revitimização para o autor é caracterizada pelo impacto das intervenções das instituições e seus/suas profissionais.

A revitimização expressa-se em intervenções inadequadas, constrangedoras e invasivas que não garantem os direitos das crianças, adolescentes e famílias. O despreparo técnico e, não raro, o desconhecimento da legislação destinada a essa população, em especial, as situações de violência sexual, tem sido os propulsores para a oferta de um atendimento distante da perspectiva de humanização e integralidade.

O atendimento especializado, ou seja, aquele que busca garantir o direito da criança e adolescente a ser protegido deve considerar que "O ser humano não é abstrato. É real e singular. Tem cor, sexo, classe social, idade. Sua condição social específica determina, em sua luta por garantia a ampliação da dignidade, a criação de novos direitos" (LUZ; PAIVA; ROSENO, 2012, p. 54-55).

Para que essas mediações sejam conectadas ao atendimento, é imprescindível que os/as profissionais possuam subsídios para análise da realidade e posteriormente intervenham de forma crítica e ética. Pode-se afirmar que é impossível construir intervenções qualificadas sem "produzir informações e conhecimento" (MARCONSIN, 2016, p. 104).

Assim, somente se identificarão as particularidades de vida de cada criança e adolescente se houver o registro das informações, que podem ser classificadas da seguinte forma:

\footnotetext{
- No contexto institucional - estrutura, objetivos institucionais, relações internas, correntes de opinião existentes, concepções de sociedade e de trabalho social, correlação de forças etc.;

- No contexto econômico, político e sociocultural em que se situa a instituição, considerando que tanto o contexto quanto à instituição são parte intrínseca de nossa formação social, buscando entender os grupos organizados, as lutas que se desenvolvem, a correlação de forças entre as classes e frações de classe na sociedade, os movimentos sociais existentes, as redes de intervenção social, as possíveis políticas de alianças e outras;
} 
- No contexto da população usuária - composição de classe, de gênero, raça/etnia, faixa etária, costumes, valores, estereótipos, formas de vida e lazer, de luta, condições de moradia, atividades econômicas, saneamento básico, infraestrutura do local onde habita, etc. (MARCONSIN, 2016, p. 105).

É preciso criar uma cultura institucional e profissional que valorize o registro das informações, não apenas como uma prática burocrática de comprovação de ações e alcance de metas, mas sobretudo de subsídio aos processos interventivos.

Para intervir diante da complexidade da violência é preciso que os/as profissionais e gestores conheçam esse fenômeno em seu âmago, entendam e discutam as particularidades, Como se manifesta? Por que acontece? Onde? Quais crianças e adolescentes são mais suscetíveis a violência? Quem comete a violência? Quais são as determinações?

Em síntese, é necessário apreender a violência contra crianças e adolescentes para além do invólucro da imediaticidade sobre a família, e assim considerar que a multidimensionalidade é produzida no âmbito macrossocial (relações sociais, políticas e econômicas), no âmbito institucional (relações das instituições com a população usuária de seus serviços) e relacional (relações entre as pessoas - familiares e comunitárias).

Será somente com o registro e sistematização das situações de violência, com a produção de um conhecimento não fragmentado que os procedimentos institucionais e profissionais poderão ser consolidados, a fim de viabilizarem ações preventivas e protetivas por meio do aprimoramento de técnicas e trocas interdisciplinares.

\section{Registros Institucionais que silenciam as particularidades da violência contra crianças e adolescentes}

A pesquisa iniciou o processo de coleta de dados em 2018. Para a elaboração deste artigo, foram submetidos ao trato analítico 58 prontuários de crianças e adolescentes em situação de violência atendidas em uma instituição de um Município da Fronteira Oeste do Rio Grande do Sul (entre os anos de 2016 a 2018/1).

A proposta inicial era coletar os dados via pesquisa documental, considerando que esse procedimento metodológico "é apropriado quando se deseja investigar um fenômeno já ocorrido e se estendeu por determinado tempo, buscando criar numa linha do tempo comportamentos de um determinado evento" (KRIPKA; SCHELLER; BONOTTO, 2015, p. 246). Devido à insuficiência de dados registrados nos documentos institucionais, o corpus da 
pesquisa foi ampliado $^{1}$, no sentido de buscar mais elementos que possibilitassem o dimensionamento da violência contra crianças e adolescentes.

A ausência de dados confiáveis já foi apontada pelo Tribunal de Contas da União em 2004:

Acresce-se, ainda, como fator complicador no atendimento especializado, a insuficiência de dados registrados sobre os atendimentos e encaminhamentos para a rede, como hospitais, escolas, abrigos e a pouca clareza no que tange o acompanhamento das vítimas, demonstrando uma falta de sistematização dos procedimentos e evidenciando a carência de monitoramento e supervisão técnica dos governos estaduais, municipais e federal (PAIXÃO; DESLANDES, 2010, p. 122).

O registro de informações sobre a violência é de suma importância, uma vez que crianças e adolescentes estão entre o segmento populacional que mais sofre com a violência no Brasil. Segundo dados do Disque 100, das 133.061 denúncias recebidas pelo serviço em 2016, 76.171, representando 57\% do total, são de violações aos direitos infantojuvenis.

O quadro 1 evidencia que, entre as violências que mais assolaram as crianças e adolescentes no município estudado, em 2017, está a negligência. Seguida da violência física e violência sexual (abuso e exploração sexual), corroborando com a realidade nacional. $\mathrm{Na}$ sequência, o quadro 2 demonstra o quantitativo de crianças e adolescentes que receberam atendimento especializado e as violências sofridas.

Quadro 1: Denúncias registradas pelo Conselho Tutelar em 2017

\begin{tabular}{|c|c|}
\hline \multicolumn{2}{|c|}{ Denúncias registradas pelo Conselho Tutelar - 2017 } \\
\hline Negligência & 149 \\
\hline Abuso Sexual & 28 \\
\hline Exploração Sexual & 18 \\
\hline Violência Física & 75 \\
\hline Violência Psicológica & 0 \\
\hline Total & 270 \\
\hline
\end{tabular}

Fonte: Sistematização das autoras, 2019.

\footnotetext{
${ }^{1}$ Para a elaboração deste artigo, foram utilizadas apenas as informações coletadas por meio de pesquisa documental.
} 
Quadro 2: Atendimentos registrados nos documentos analisados em 2017

\begin{tabular}{|c|c|}
\hline \multicolumn{2}{|c|}{ Atendimentos Registrados - 2017 } \\
\hline Negligência & 4 \\
\hline Violência Sexual & 14 \\
\hline Violência Física & 4 \\
\hline Violência Psicológica & 0 \\
\hline Total & 21 \\
\hline
\end{tabular}

Fonte: Sistematização das autoras, 2019.

Os quadros possibilitam identificar um hiato entre os dados referentes à denúncia em comparação com os dados de atendimento às crianças e aos adolescentes no ano de 2017. Tal fenômeno pode ser apreendido sob duas diretrizes explicativas.

Primeiro, o processo de confirmação da violação de direitos: cabe ao Conselho Tutelar verificar a existência da violência e encaminhar as crianças, adolescentes e respectivas famílias para as entidades de atendimento da rede de proteção. O Conselho Tutelar ao averiguar a inexistência de situações e fatores violadores aos direitos dessa população procede ao arquivamento do caso e/ou encaminhamento para algum serviço de atenção preventiva ou para as demais políticas sociais.

E segundo, rota crítica: diz respeito ao caminho que as crianças, adolescentes e as famílias percorrem na busca pelo rompimento com a violência, acrescentando-se nesse trajeto os obstáculos institucionais, políticos e estruturais que não raras vezes incidem para que a violência permaneça no silêncio.

A denominação Rota Crítica surge em 2000, como iniciativa da Organização PanAmericana da Saúde (OPAS), para apreender a violência de gênero e o percurso que a mulher realiza para romper com a violência, introduzindo a sequência de decisões tomadas e ações executadas durante esse processo.

La Ruta empieza con la decisión y determinación de las mujeres de apropiarse de sus vidas y las de sus hijos. Siguiendo esta Ruta, conocemos los factores que impulsan a 
las mujeres a buscar ayuda, las dificultades encontradas para llevar adelante tal decisión, sus percepciones sobre las respuestas institucionales, y las representaciones sociales y significados sobre la violencia intrafamiliar que existen entre el personal de las instituciones que deben ofrecer respuestas a este serio problema de salud pública. Al fin, aprendemos sobre sus frustraciones y resignaciones que, en muchos casos, las Ilevan otra vez a la situación de violencia (SAGOT, 2000, p. 07).

A aproximação da proposta da Rota Crítica com o percurso que as crianças e adolescentes em situação de violência percorrem possibilita entender que a disparidade entre os quantitativos de denúncia e atendimento poderá estar relacionada à fragilidade e/ou à ausência de ações da rede de proteção, no que tange ao atendimento e também à prevenção e à sensibilização da comunidade para a ruptura de posturas reprodutoras da violência.

Diante desse enredo, é explícita a necessidade e urgência da construção de uma política pública municipal de enfrentamento à violência neste município. O Plano Municipal de enfrentamento à violência contra crianças e adolescentes é um instrumento que visa edificar um conjunto de ações integralizadas, para a garantia dos direitos infantojuvenis, representando dessa forma:

[...] uma carta de diretrizes e princípios que orienta as ações a serem desenvolvidas no âmbito do município. A construção desse documento é um ato de democracia, em que através do detalhamento de cada objetivo, estabelecem-se as prioridades de curto, médio e longo prazo para a garantia dos direitos das crianças e adolescentes (VIEIRA, 2013, p. 114).

A municipalização das ações destinadas ao atendimento de crianças e adolescentes, surge enquanto estratégia para o fortalecimento da rede de proteção e promoção aos direitos. O município é vislumbrado como eixo fundamental e lócus privilegiado para a materialização das ações, buscando-se assim uma maior proximidade, entre a formulação de políticas para o atendimento e a demanda que se apresentam às instituições responsáveis pela atenção.

Além disso, os quadros ( 1 e 2 ) revelam a invisibilidade da violência psicológica contra crianças e adolescentes no município, entendida de acordo com a Lei no $13.431 / 2017^{2}$, como sendo:

II) Violência Psicológica:

\footnotetext{
${ }^{2}$ Esta Lei tem como objetivo normatizar e organizar o sistema de garantia de direitos da criança e do adolescente vítima ou testemunha de violência e cria mecanismos para prevenir e coibir a violência em todas as manifestações.
} 
a) Qualquer conduta de discriminação, depreciação ou desrespeito em relação à criança ou ao adolescente mediante ameaça, constrangimento, humilhação, manipulação, isolamento, agressão verbal e xingamento, ridicularização, indiferença, exploração ou intimidação sistemática (bullying) que possa comprometer seu desenvolvimento psíquico ou emocional;

b) $\mathrm{O}$ ato de alienação parental, assim entendido como a interferência na formação psicológica da criança ou do adolescente, promovida ou induzida por um dos genitores, pelos avós ou por quem os tenha sob sua autoridade, guarda ou vigilância, que leve ao repúdio do genitor ou que cause prejuízo ao estabelecimento ou à manutenção de vínculo com este;

c) Qualquer conduta que exponha a criança ou o adolescente, direta ou indiretamente, a crime violento contra membro de sua família ou de sua rede de apoio, independentemente do ambiente em que cometido, particularmente quando isto a torna testemunha.

Por ser uma violência que não deixa marcas visíveis nas crianças e adolescentes e por reproduzir-se invisivelmente nas relações interpessoais, ferindo a subjetividade dos sujeitos (emocional e cognitiva), o processo de identificação e denúncia é mais difícil. A marca visível da violência ainda está presente no ideário social, contrapondo-se às prerrogativas do ECA que, no art. 13, prevê que as denúncias devem acontecer não somente com a confirmação, mas também com a suspeita de maus-tratos.

Quanto ao perfil das crianças e adolescentes, os dados nacionais revelam que a maioria das vítimas são meninas, $44 \%$. No recorte cor/etnia, crianças e adolescentes negros e pardos somam $58 \%$ das vítimas. Tais dados, indicam que crianças e adolescentes do sexo feminino e na cor negra e/ou parda são a população mais vulnerável ao acometimento de diversas expressões da violência.

Particularizando com os dados coletados no município, a realidade não se distancia, ao contrário, exprime que as vítimas de violência têm idade e gênero. Entre os anos de 2016 e 2018/1 foram atendidas 23 meninas e 16 meninos, representando uma diferença de 18\%, assim pode-se identificar que meninas sofrem mais com situações de violência no Município.

Os dados referentes à faixa etária possuem significativa variação, entre os anos de 2017 e 2018/1 o grupo etário dos 03 aos 08 anos de idade foi predominante nos registros de atendimento. No entanto, entre os anos de 2016 e 2017, a faixa etária prevalecente fora de adolescentes entre 12 e 14 anos, demostrando uma variação entre crianças e adolescentes. Em relação aos dados nacionais, é possível observar que:

[...] a maioria das vítimas está na primeira infância (0 a 7 anos), com destaque para a faixa etária de 4 a 7 anos. Esse grupo soma 38,80\% das denúncias relacionadas à violação de direitos de crianças e adolescentes. As meninas e meninos entre 8 e 11 
anos representam 20,49\% e os adolescentes (12 a 17 anos) são 30,04\% (BRASIL 2018, p.22).

A cor/etnia das crianças e adolescentes não foi encontrada nos documentos. Dessa forma, não há dados municipais que possibilitem apreender se a cor das crianças torna-as mais vulneráveis à vitimização. Sabe-se que crianças e adolescentes negras e pardas são mais suscetíveis a serem vítimas de violência. As disparidades de gênero e a discriminação étnicoracial aumentam os riscos dessa população vir a ter os direitos violados. Os dados nacionais revelam que a:

A violência letal, com recorte em gênero e raça/etnia, é alarmante. As taxas de homicídio de brancas caem na década analisada (2003 a 2013): de 3,6 para 3,2 por 100 mil, queda de 11,9\%; enquanto as taxas entre as mulheres e meninas negras crescem de 4,5 para 5,4 por 100 mil, aumento de 19,5\%. Com isso, a vitimização de negras, que era de 22,9\% em 2003, cresce para 66,7\% em 2013 (BRASIL, 2018, p. 69).

A realidade da infância e da adolescência pobre no país é uma amálgama que reúne desproteção, abandono e vitimizações. Entretanto, é imprescindível considerar que não é somente a pobreza, na carência de recursos materiais, que contribui para a exposição de crianças e adolescentes à violência, é todo um complexo de ausências que transcendem o âmbito material, diz respeito a uma série de privações (sociais, culturais e espirituais).

\begin{abstract}
As crianças são especialmente vulneráveis às violações de direitos, à pobreza e à iniquidade no País. Por exemplo, $29 \%$ da população vive em famílias pobres, mas, entre as crianças, esse número chega a $45,6 \%$. As crianças negras, por exemplo, têm quase $70 \%$ mais chance de viver na pobreza do que as brancas; o mesmo pode ser observado para as crianças que vivem em áreas rurais. Na região do Semiárido, onde vivem 13 milhões de crianças, mais de $70 \%$ das crianças e dos adolescentes são classificados como pobres. Essas iniquidades são o maior obstáculo para o alcance dos Objetivos de Desenvolvimento do Milênio (ODM) por parte do País. [...] A cada dia, 129 casos de violência psicológica e física, incluindo a sexual, e negligência contra crianças e adolescentes são reportados, em média, ao Disque Denúncia 100. Isso quer dizer que, a cada hora, cinco casos de violência contra meninas e meninos são registrados no País. Esse quadro pode ser ainda mais grave se levarmos em consideração que muitos desses crimes nunca chegam a ser denunciados (UNICEF, 2015, on-line).
\end{abstract}

O perfil apresentado pelos dados nacionais que meninas, negras e pobres são mais suscetíveis às vitimizações não pode ser particularizado para a realidade municipal, pois no processo de análise documental não consta a condição socioeconômica da criança e da família, tampouco a cor/etnia, inviabilizando a construção do perfil infantojuvenil que é atendido pela instituição.

Os dados municipais demostram que o vínculo entre a criança e o/a autor/a da 
A invisibilidade da violência contra crianças e adolescentes: Análise cartográfica do fenômeno...

violência expressa-se nos seguintes percentuais: $37 \%$ padrasto, $20,3 \%$ pais, enquanto os desconhecidos somam apenas $6 \%$, evidenciando que a violência contra crianças e adolescentes acontece, na maioria das vezes, no âmbito familiar.

A construção do perfil do/a autor/a da violência foi impossibilitada pela ausência de dados nos documentos analisados. Ainda que não seja o foco da instituição o atendimento aos sujeitos que cometem a violência, é imprescindível conhecer a relação do/a autor com as crianças, uma vez que as pesquisas nacionais vêm apontando que é em casa, que grande parte das violências acontecem.

[...] a exclusão do(a) agressor(a) dos processos de intervenção é, também, uma das inadequações dos serviços e que contribuem para que a violência seja silenciada, pois sem a oferta de um tratamento e/ou acompanhamento a probabilidade do agressor mudar suas atitudes é reduzida, o que compromete ainda mais a saúde e o desenvolvimento de crianças e adolescentes, pois, provavelmente, continuarão convivendo com constantes agressões, atos abusivos e negligentes (SCHEK, 2018, p. 05).

No município pesquisado, não existem serviços de atendimento psicossocial aos sujeitos que cometem violência contra crianças e adolescentes, evidenciando uma imensa fratura para a integralidade do enfrentamento a essa expressão da questão social. Para Arantes (2007), é fundamental que a rede de proteção não se deixe aprisionar pela lógica da responsabilização meramente jurídica, mas atue para o resgate da dignidade e garantia dos sujeitos que cometeram violência.

A superação do modelo restrito ao caráter punitivo, que reforça e legitima os processos de exclusão, estigma e julgamento moral dos/as autores/as de violência, desenhase a partir da atenção do Poder Público, para a disponibilidade de atendimentos qualificados.

O enfoque da política de enfrentamento à violência deve ser a proteção e promoção dos direitos da criança e do adolescente, sob a perspectiva da integralidade das ações. A articulação entre as políticas públicas tem como escopo tornar as ações mais eficientes, sendo, na atualidade, o caminho que mais apresenta efetividade social para a construção de uma política integral de proteção dos direitos da infância e juventude.

\section{Considerações Finais}

Primordialmente, é imprescindível salientar que as contribuições da pesquisa foram 
tecidas na perspectiva de elaborar, pela primeira vez, no município, dados estatísticos e informacionais sobre a situação da violência contra o segmento infantojuvenil. É notório que, para a construção de políticas públicas concatenadas às particularidades da realidade local, é diametral a identificação da violência por meio de dados mensuráveis que possibilitem conhecer as peculiaridades da violência, perfil sociodemográfico das crianças, adolescentes, famílias e dos/as autores/as da violência, assim como das modalidades de atendimento e encaminhamento realizados.

A realidade dos registros vem evidenciando uma barreira significativa para a construção de dados confiáveis sobre esse fenômeno, uma vez que as informações disponíveis nos prontuários são superficiais e desconexas. A partir dessa constatação empírica, a pesquisa segue compromissada em contribuir com subsídios teórico-práticos, para a organização dos documentos institucionais, a fim de promover um olhar ampliado dos/as profissionais sobre a importância do registro completo das particularidades da violência contra crianças e adolescentes.

Há a necessidade de gerir as informações de forma que estas contribuam com dados dimensionais da violência, por meio de um processo de sistematização e unificação, bem como da gestão dessas informações no que tange à dimensão da violência contra crianças, denúncias (suspeita e confirmação), encaminhamentos realizados (Conselho Tutelar, Delegacia de Polícia, Política de Assistência Social - Serviços de Média e Alta Complexidade, Política de Saúde, Educação, etc.).

A materialização de uma política municipal de enfrentamento à violência requer primeiramente, a construção do Plano Municipal, que permitirá descentralizar poderes e fortalecer a participação da população local nas decisões relativas à proteção dos direitos infantojuvenis.

Por fim, imputa-se, nesse movimento, a articulação entre o município e as universidades para o desenvolvimento de pesquisas e produção do conhecimento como estratégia para qualificar as ações, apropriando-se da multiplicidade de fatores que circundam a questão pela integralização dos dados, possibilitando um dimensionamento mais fidedigno às particularidades da violência.

\section{Referências}

ARANTES, E. de M. Redes de proteção e de responsabilização em casos de violência sexual 
contra crianças e adolescentes. IN: OLIVEIRA, A. C. et al. Violência contra crianças e adolescentes: rede de proteção e responsabilização. Vol. 1. Rio de Janeiro: Nova Pesquisa e Assessoria em Educação, 2007.

BEN NATAN, M. et al. Factors affecting medical and nursing staff reporting of child abuse. Internacional Nursing Review, Geneva, v. 59, n. 3, p. 331-337, set. 2012. Disponível em: < https://www.ncbi.nlm.nih.gov/pubmed/22897183>. Acesso em: 1 de dezembro de 2018.

BRASIL. Direitos da Criança e Adolescente. Violência contra Crianças e Adolescentes: Análise de Cenários e Propostas de Políticas Públicas. Ministério dos Direitos Humanos. Secretaria Nacional de Proteção dos / Moreschi, M. T. - Documento eletrônico - Brasília: Ministério dos Direitos Humanos, 2018. Disponível em: < http://www.mdh. gov.br/biblioteca/consultorias/conada/violencia-contra-criancas-e-adolescentes-analise-decenarios-e-propostas-de-politicas-publicas.pdf>. Acesso em: 15 de novembro de 2018.

BRASIL. Educação sem violência: um direito de crianças e adolescentes.

Ministério dos Direitos Humanos. Secretaria Nacional de Proteção dos Direitos da Criança e Adolescente / Passos T. C. A.- Documento eletrônico - Brasília: Ministério dos Direitos Humanos, 2018. Disponível em: < http://www.mdh.gov.br/biblioteca Lconsultorias/conada/educacao-sem-violencia-um-direito>. Acesso em: 01 de dezembro de 2018.

BRASIL. Orientações Técnicas: Centro de Referência Especializado de Assistência Social CREAS. Secretaria Nacional de Assistência Social. Ministério do Desenvolvimento Social e Combate à Fome - MDS. Proteção Social Especial. Brasília, 2011

BRASIL. Relatórios de registros gerais de denúncia do Disque Direitos Humanos (Disque 100) 2011-2017. Secretaria de Direitos Humanos. Brasil, 2017.

CONEP. Comissão Nacional de Ética em Pesquisa. Resolução no 510, de 07 de abril de 2016. Conselho Nacional de Saúde. Ministério da Saúde. Disponível em: < $\underline{\text { http: } / /}$ conselho.saude.gov.br/resolucoes/2016/Reso510.pdf>. Acesso em: 20 de março de 2019.

FILHO, K. P.; TITE, M. M. A cartografia como método para as ciências humanas e sociais. Barbarói, Santa Cruz do Sul, n.38, p., jan./jun. 2013. Disponível em: < http: //pepsic.bvsalud.org/scielo.php? script=sci_arttext\&pid=S0104-65782013000100 004>. Acesso em: 26 de novembro de 2018.

GIL, A. C. Como Elaborar Projetos de Pesquisa. 4.ed. São Paulo: Atlas, 2007.

IAMAMOTO, M. V. O Serviço Social na Contemporaneidade: trabalho e formação profissional. São Paulo, Cortez, 2008

KRIPKA, R.; SCHELLER, M.; BONOTTO, D. L. Pesquisa Documental: considerações sobre conceitos e características na Pesquisa Qualitativa. Investigação Qualitativa em Educação /Investigación Cualitativa en Educación. Volume 2. Disponível em: < https:// 
proceedings.ciaiq.org/index.php/ciaiq2015/article/view/252>. Acesso em: 20 de novembro de 2018.

LUZ, F.; PAIVA, L., ROSENO, R. O Desafio da resposta da sociedade e do Estado quando a vítima da violência sexual é criança ou adolescente. IN: BRASIL. Comitê Nacional de Enfrentamento à Violência Sexual contra Crianças e Adolescentes. Proteger $e$ Responsabilizar: O desafio quando a vítima da violência sexual é criança ou adolescente. Brasília, 2012.

MARCONSIN, C. Documentação em Serviço Social: debatendo a concepção burocrática e rotineira.In: FORTI, V.; GUERRA, Y. (coords). Serviço Social: temas, textos e contextos. 5. ed. rev. amp. Rio de Janeiro: Lumen Juris, 2016.

NORDENSTAHL, U. C. E. Dónde está la víctima? apuntes sobre victimologia. Buenos Aires: Librería Histórica, 2008.

PAIXÃO, A. C. W.; DESLANDES, S. F. Análise das Políticas Públicas de Enfrentamento da Violência Sexual Infantojuvenil. Saúde Soc. São Paulo, v.19, n.1, p.114-126, 2010. Disponível: <http://www.scielo.br/pdf/sausoc/v19n1/09.pdf>. Acesso em: 10 de novembro de 2018.

SAGOT, M. Ruta crítica de las mujeres afectadas por la violencia intrafamiliar en américa latina (estudios de caso de diez países). Organización Panamericana de la Salud. Programa Mujer, Salud y Desarrollo, 2000. Disponível em: <http://apps.who. int/iris/bitstream/handle/10665/165880/9275323348.pdf;jsessionid=A61979F1CABAFC358A 5C08EBC575F371?sequence=1>. Acesso em: 20 de julho de 2016.

SCHEK, G. et al. Práticas Profissionais que Silenciam a Violência Intrafamiliar contra crianças e adolescentes. Texto Contexto Enferm, 2018; 27(1). Disponível em: <http:

//www.scielo.br/pdf/tce/v27n1/0104-0707-tce-27-01-e1680016.pdf>. Acesso em: 1ㅇ de dezembro de 2018.

UNICEF. A Familiar Face: Violence in the lives of children and adolescents. Disponível em: < http://www.unicef.org/brazil/pt/activities.html>. Acesso em: 24 de maio de 2018.

VIEIRA, M. S. Enfrentamento da violência sexual infanto-juvenil em Porto Alegre: contradições e perspectivas / Vieira, M. S. - Porto Alegre, 2013. Disponível em: < http://tede2.pucrs.br/tede2/bitstream/tede/537/1/445561.pdf >. Acesso em: 23 de novembro de 2018.

VIEIRA, M. S. Rompendo o silêncio: o enfrentamento da violência sexual infanto-juvenil no âmbito dos CREAS tocantinenses. Tese de Doutorado em Serviço Social. Pontifícia Universidade Católica do Rio Grande do Sul. Porto Alegre, 2015. Disponível em: < http: //repositorio.pucrs.br/dspace/handle/10923/7603>. Acesso em: 12 de novembro de 2018. 